\title{
Study at the Bolted Joint Assembly with Slotted Hole
}

\author{
Ramadhan Prasetya Utama ${ }^{1}$ and Alain Daidié ${ }^{2}$
}

\begin{abstract}
The bolt as an element which integrates several small parts to a united big structure had been used since a long time ago. This type of impermanent joint holds many advantages in the engineering field such as facilitating the maintenance, particularly at the change of defected part, and also making the delivery of many parts composing a huge structure more sensible by transporting them in diverse modes of transport. One of problems using this type of joint is sometimes it is difficult to assure holes position between parts to be aligned just as designed, in order to facilitate positioning of parts during assembly we could possibly use parts with slotted hole. However, a slotted hole will result in a reduced contact surface between the bolt and parts assembled, therefore the behavior of this type will be clearly different compared to the assembly with normal hole. The research will be conducted with assistance of a finite elements software ABAQUS® for simulating the model along with its parameters and mathematical software Matlab ${ }^{\circledR}$ for interpolating data obtained from the simulation. Firstly, the model will be validated by comparing it to experimental result of research conducted by Bakhiet[1], then its boundary conditions and mesh will be used to next model simulations. Secondly, the parameters of the assembly will be varied such as bolt positions on the part and the modulus Young ratio of bolt and parts. Finally, both assemblies are to be compared (e.g. with normal and slotted hole) and then the assembly's critical value is to be found by using dimensionless parameters developed by Turgeon and Vadean[2]. From research conducted, we could conclude that the behavior of the assembly, particularly at its fatigue stress produced at the bolt, changes significantly with the variation of the bolt position and also the modulus Young ratio of the bolt and part. A reduced value of fatigue stress produced will be achieved while the bolt position is the nearest possible with respect to the point where load applied. Whereas, a higher modulus Young ratio will convict a higher fatigue stress produced at the bolt.
\end{abstract}

Keywords—Slotted hole, bolt, finite elements, joint.

\section{INTRODUCTION}

B olted joint assembly is an inseparable element in designing step of the complex mechanical structure. Because joints represent the weakest potential point at the structure, the design of joints should be having an important influence in the integrity of the structure and maximum load hold globally by the structure.

Furthermore, the bolted joint assembly is also the assembly system mostly utilized in engineering construction. A great number of its use could be found in mechanical structure. Indeed, for example at the airplane construction, the joint with respect to its technical significance holds the third most important role after the motor and the devices.

In other hand, the joint allow the process of reparation and maintenance of the system easier because we only have to change one defected part with the spare part. The delivery problem could also be resolved using this type of assembly, we could easily transport the parts of the structure for finally assembled at the destined site.

The problem faced in the bolted joint assembly is the significant difference between the statical resistance compared to the bolt resistance while being applied by the fatigue load. The fatigue resistance is found to be really low compare to its static resistance. So it is clearly sure that the type of the load applied should be taken into account. Here in this research, we will apply the eccentrical load at the end of the part which creates the eccentrical condition with respect to the bolt position. One should know that the fatigue stress happens when the variation of the bolt force and moment between the

${ }^{1}$ Ramadhan Prasetya Utama is with Departement of Mechanical Engineering and Aeronautics, Université Paul Sabatier, Toulouse, France. E-mail: prazetya.utama@gmail.com.

${ }^{2}$ Alain Daidié is with Departement of Mechanical Engineering, Institute Nationale des Sciences Appliquées de Toulouse, Toulouse, France. E-mail: alain.daidie@insa-toulouse.fr. initial condition and the loaded condition does exist, and the eccentrical load accelerates this condition.

This research will be focused on obtaining the fatigue critical value of the bolted joint assembly with slotted hole with the assistance of dimensionless parameters such as external force to preload $(\mathrm{Fe} / \mathrm{Q})$, the increase of bolt force to preload $(\Delta \mathrm{Fb} / \mathrm{Q})$, and the increase of bolt moment to preload and bolt nominal diameter $(\Delta \mathrm{Mb} /(\mathrm{Q} . \mathrm{D}))$. The data will be extracted by finite elements simulation which is conducted on ABAQUS®.

\section{METHOD}

\section{A. Fatigue Resistance}

The dynamic resistance of a threaded element is different to its statical resistance. Normally, the statical resistance of a bolt will always be higher compared to its dynamic resistance, the stress concentration at the first engaged thread and the plastification are suspected to cause this decreasing value of bolt resistance. The standard VDI 2230 and E25-030 take into account those two causes at the high resistance bolt as the function of resistance section, based in the theoretical Wohler curve (as shown at figure 1) and the axial loading of fatigue. It could have been seen that the reduction of bolt diameter used will also augment the fatigue resistance of the bolt.

Indeed, the fatigue loading is the consequence of the normal stress variation between preloaded state and loaded one. Then, this variation results in emerging traction force and bending moment. Generally, the fatigue stress is caused by these two variations at the bolt. The fatigue stress could be calculated by these following equations:

$$
\begin{aligned}
& \sigma_{\text {fatigue }}=\frac{\Delta F_{B}}{2 A_{S}}+\frac{d_{s} \cdot \Delta M_{B}}{4 I_{S}} \\
& I_{S}=\frac{\pi d_{s}{ }^{4}}{64}
\end{aligned}
$$




\section{B. Research at The Bolted Joint Assembly Loaded by High Eccentrically Load by Using Dimensionless Parameters}

On prior research undergone by Turgeon and Vadean, it is found that regrouping the assembly based on the same geometrical characteristic is very efficient and useful in order to study the behavior of bolted joint assembly. The supplementary force and bending moment at the bolt, and the external force are written in form of ratio divided by the applied preload at the bolt, $\left(\Delta \mathrm{F}_{\text {Bolt }} / \mathrm{Q}\right),\left(\Delta \mathrm{M}_{\mathrm{Bolt}} / \mathrm{Q} . \mathrm{D}\right)$, and $\left(\mathrm{F}_{\text {External }} / \mathrm{Q}\right)$ respectively. The preload itself is used in order to increase the bolt's fatigue resistance by reducing the supplementary force at the bolt. It also causes the increase of load needed to separate the parts assembled. Then, by keeping the same geometrical ratio of the assembly, one can find the same value of $\left(\Delta \mathrm{F}_{\mathrm{Bolt}} / \mathrm{Q}\right)$ and $\left(\Delta \mathrm{M}_{\mathrm{Bolt}} / \mathrm{Q} . \mathrm{D}\right)$ at the same value of $\left(\mathrm{F}_{\text {External }} / \mathrm{Q}\right)$ at any bolt nominal diameter and any preload given to the bolt. The value of $\left(\Delta \mathrm{F}_{\mathrm{Bolt}} / \mathrm{Q}\right)$ as the function of $\left(\mathrm{F}_{\text {External }} / \mathrm{Q}\right)$ at varied value of preloads and bolt nominal diameter are shown on figure 2 and figure 3.

The objective of these dimensionless parameters are to generalize and regroup the assembly based on its geometrical ratio with respect to bolt nominal diameter used without taking into account the choice of bolt nominal diameter and preload to be applied. At the end of this research, it has been found that only the ratio of modulus Young of bolt and part has the effect to the behaviour of the assembly. So, instead of messing around on varying the part's material, one had better take into account only the modulus Young ratio of the bolt and part $\left(\mathrm{E}_{\mathrm{bolt}} / \mathrm{E}_{\mathrm{part}}\right)$.

One could see at the curve (figure 5) when the ratio $\left(\mathrm{E}_{\mathrm{bolt}} / \mathrm{E}_{\mathrm{part}}\right)$ is decreasing, in other words the bolt becomes more flexible than the part, the ratio $(\triangle F b / Q)$ is also found decreasing which implies the reduction of fatigue stress and then extend the lifetime of the bolt.

From this research, one could conclude that if assemblies have the same geometrical proportion with respect to bolt nominal diameter and the same modulus Young ratio of bolt and part then it will be no more useful varying the bolt nominal diameter and applied preload.

\section{Modifying Fatigue Stress Equation as the Function of Value $\Delta F_{\text {Bolt }} / Q$ and $\Delta M_{\text {Boll }} / Q . D$}

In this section, the author would like to modify the fatigue stress equation so that it will change as the function of dimensionless parameters such as $\Delta \mathrm{F}_{\mathrm{Bol}} / \mathrm{Q}$ and $\Delta \mathrm{M}_{\mathrm{Bolt}} / \mathrm{Q}$.D. By modifying this equation, one could find the fatigue maximum value before the bolt fails without taking into account the choice applied preload as well as the bolt nominal diameter.

$$
\begin{aligned}
\sigma_{\text {fatigue }} & =\frac{\Delta F_{\text {Bolt }}}{2 . A s}+\frac{\Delta M_{\text {Bolt } . D}}{4 . I_{S}} . \\
\text { where } I_{S} & =\frac{\pi d_{s}^{4}}{64} \\
\sigma_{\text {fatigue }} & =\left(\frac{\Delta F_{\text {Bolt }}}{Q}\right) \frac{Q}{2 . A s}+\frac{\Delta M_{\text {Boulon } . D .64}}{4 . \pi \cdot D^{4}} \\
\sigma_{\text {fatigue }} & =\left(\frac{\Delta F_{\text {Bolt }}}{Q}\right) \frac{Q}{2 . A s}+\left(\frac{\Delta M_{\text {Bolt }}}{Q . D}\right) \frac{Q . D^{2} \cdot 4 \cdot 16}{4 . \pi \cdot D^{4}}
\end{aligned}
$$

$$
\begin{aligned}
& \sigma_{\text {fatigue }}=\left(\frac{\Delta F_{\text {Bolt }}}{Q}\right) \frac{Q}{2 . A s}+\left(\frac{\Delta M_{\text {Bolt }}}{Q . D}\right) \frac{16 . Q}{4 . A s} \\
& \sigma_{\text {fatigue }}=\left(\frac{1}{2} \frac{\Delta F_{\text {Bolt }}}{Q}\right) \frac{Q}{A s}+\left(4 \frac{\Delta M_{\text {Bolt }}}{Q . D}\right) \frac{Q}{A s} \\
& \sigma_{\text {fatigue }}=\left(\frac{1}{2} \frac{\Delta F_{\text {Bolt }}}{Q}+4 \frac{\Delta M_{\text {Bolt }}}{Q . D}\right) Q_{(M P a)}
\end{aligned}
$$

Then, in order to avoid the failure of fatigue which means when the fatigue stress reaches the $50 \mathrm{MPa}$ (the fatigue stress limit for a bolt having bolt nominal diameter $12 \mathrm{~mm}$ ), one should limit the value such as shown below :

$$
\begin{aligned}
& \sigma_{\text {limitofthefatigue }} \geq \\
& \left(\frac{1}{2} \frac{\Delta F_{B o l t}}{Q}+4 \frac{\Delta M_{B o l t}}{Q . D}\right) Q_{(M P a)}
\end{aligned}
$$

It is known that:

$$
\left(\frac{1}{2} \frac{\Delta F_{\text {Boulon }}}{Q}+4 \frac{\Delta M_{\text {Boulon }}}{Q . D}\right)=f\left(\frac{F e}{Q}\right)
$$

For a value of preload given $\mathrm{Q}_{(\mathrm{MPa})}$, one should understand which the critical value limit is, in order to ensure the fatigue failure will not occur, one should limit :

$$
\left(\frac{1}{2} \frac{\Delta F_{\text {Bolt }}}{Q}+4 \frac{\Delta M_{\text {Bolt }}}{Q . D}\right) \leq \frac{\sigma_{\text {fatigue limit }}}{Q_{(M P a)}}
$$

\section{Finite Elements Model}

In this research, we will use ABAQUS software in order to model and calculate with given parameters. Principally, there are four important components used:

1. The slotted holed part

2. The normal holed part

3. The bolt

4. The load support, this has the objective to avoid the element distortion while load is being applied

Taking into account the symmetry of the assembly, only a half of the assembly is modelled in order to reduce the calculation time. It is clear that the reduction of calculation time has always been the objective at finite element simulation study.

1) Parameters Explanation

a. $\mathrm{m}$ :distance between the bolt's axis and the end of the part which is not being applied by the force

b. n: distance between axis of the bolt and the end of part where load is being applied (force eccentricity)

c. Hp: Part thickness

d. Hr: Washer thickness

e. 2W: Part width

f. Dh: Hole diameter

2) Geometrical Dimensions

The bolt position and modulus Young ratio of bolt and part will be varied. The bolt position will use the ratio of $\mathrm{x} / \mathrm{p}=0,0.25,0.5,0.75$, and 1 where the value of 0 means that the distance between bolt's axis and point of load is on the furthest, and vice versa, the value of 1 means that distance is on the nearest. For the choice of modulus Young ratio of the bolt and the part, we will use the value $0.5,1$, and 1.5 .

3) Meshing

Meshing is the most sensitive part from finite elements simulation, because it will decide the model quality in term of precision of the result and the calculation time. 
From the table below, we could see that the model has 8940 elements in total. The calculation time will be definitely more rapid than using the entire model (17.880 elements).

In this meshing process, we have to partition the components. The idea is to obtain a structural meshing on ABAQUS ${ }^{\circledR}$ which is the hexahedron element. Based on previous research, the meshing around the hole has to be refined, finer than the other area of part in order to provide the information needed in analysis. But, one should take into account that the finer the mesh is, it is more likely to be distorted while the load is being applied. In addition, it will also increase the calculation time.

4) Boundary Conditions

There are several boundary conditions. The first one is the symmetry plan of $x-y$ which allows the modeling of one half of assembly. The second one is to be placed at the end of the part which is near to the point where load is applied, this boundary condition will block all the displacement and rotation except the displacement towards y-axis. The third one is placed at the other end of parts which is located far from the loading point, here the boundary condition used is to block the displacement towards $\mathrm{x}$-axis as well as $\mathrm{y}$-axis and the rotation at the $\mathrm{z}$ axis. The fourth one is placed at the bottom of the bolt which is encastred during preload process in order to ensure the bolt is not going to move. The last one is being placed at the bottom and upper surface of normal holed part, where these surfaces are to be encastred so that it could act as a rigid body. These all boundary conditions could be seen at the figure 10 . In order to ensure boundary conditions represent well the real behavior of the assembly, the validation process will be carried out.

5) Collecting Data Points

The stress is read at three control points of bolt, which are (1) the point that is located the furthest with respect to loading point, (2) the point that is located the neares with respect to loading point, and (3) the point which is located perpendicular the line between number 1 and 2 . These three points could be seen from figure 11 .

After having collected data from three control points, normal and bending stress are to be calculated by these following equations :

$$
\begin{aligned}
& \sigma_{\text {normal }}=\sigma_{\text {avg }}=\frac{\sigma_{1}+\sigma_{2}+2 * \sigma_{3}}{4} \\
& \sigma_{\text {bending }}=\frac{\sigma_{\max }-\sigma_{\min }}{2}=\frac{\sigma_{2}-\sigma_{1}}{2}
\end{aligned}
$$

\section{E. Model Validation}

The model validation is carried out by comparing the curve $\Delta \mathrm{F}_{\text {bolt }} / \mathrm{Q}$ versus $\mathrm{F}_{\text {external }} / \mathrm{Q}$ as well as the curve $\Delta \mathrm{M}_{\text {bolt }} / \mathrm{Q}$.D versus $\mathrm{F}_{\text {external }} / \mathrm{Q}$ generated from both of model simulation and research done by Bakhiet ${ }^{[1]}$. For the sake of simplicity, the model to be compared is the structure with normal holed part, but one should note that all boundary conditions applied are the same to ones at the model with slotted holed part.

As shown in the figure 12 and 13, values collected from model simulation are superposing experimental values from Bakhiet's research. From these graphs, it could be concluded that the finite elements model used along with its boundary conditions represents well the real behavior of the assembly.

\section{RESULT AND DISCUSSION}

\section{A. The Behavior of the Assembly as the Function of Bolt Position}

Curves of several behaviors of assembly are shown at figures below (figure 14, 15, and 16). Here is shown that the bolt position affect significantly the assembly's behavior. From the figure 14, the behavior of the assembly in term of supplementary force at the bolt as the function of external force is shown, it is found that the assembly reaches its highest bolt's supplementary force when the bolt is located furthest with respect to load point. On the contrary, the bolt's supplementary force is reduced to its lowest value when the distance between the bolt and the load point is at the nearest. Therefore, one could say that the further the eccentricity is the bigger is the supplementary force produced

From the supplementary bending moment produced, it could be found that the bolt position $=0$ gives the lowest value, it could be explained by taking into account the small contact surface at the front half of bolt (with respect to load point) which transfers the external force and the big contact surface at the back half of bolt which will transfer a reaction force and counter the bending effect of applied external force. It will result to the reduction of stress difference between maximum and minimum stress at the bolt.

Finally, we will focus on the fatigue stress produced which is our objective to cut it down. From the calculation, we have generated a curve that represents the change of fatigue stress as the function of external force applied. The lowest fatigue stress is found at the bolt position $=1$ and, vice versa, the largest fatigue stress is found where boltposition $=0$. For the rest positions, one could see curves are almost superposing each other. To put it in a nutshell, one has to simply take into account only the nearest and furthest bolt position because for the other positions the fatigue stress will always fall between the value of nearest and furthest bolt position.

\section{B. The behavior of the assembly as the modulus Young ratio varies}

We are also interested in knowing what effect the modulus Young ratio has on the assembly's behavior. The curve has been generated at the figure 17. It is clearly shown on the figure that the bigger the modulus Young ratio is the faster is the fatigue stress reaching its fatigue limit. The meaning of this phenomenon is when we are choosing the bolt which is less rigid than the part, we will get better fatigue resistance. This is because the supplementary bolt force and bending moment are reduced, it results in the reduction of fatigue stress which extend the lifetime of bolt. This result is also confirmed by research carried out by Guillot[3] which states that the best performance of bolted assembly could be achieved by using flexible bolt to rigid parts.

\section{The comparison between slotted holed and normal holed assembly}

The comparison of fatigue stress between the assembly with normal hole and slotted hole is to be compared. As shown in figure 18 , one could see that, for bolt position 0.5 and 0 the fatigue stress produced at slotted holed assembly is relatively smaller than normal holed one. Only at bolt position $=1$ where the fatigue stress at 
slotted holed assembly is slightly greater than normal holed one.

From figure 19, we could see one of components composing the fatigue stress, which is bolt supplementary force $(\Delta \mathrm{Fb})$, gives a smaller value when the assembly uses slotted holed part. Generally, the evolution of bolt supplementary force is the same between slotted holed and normal holed, where we could see from the figure the force eccentricity still affects significantly this value. The further the distance is, the greater is the bolt supplementary force.

From figure 20, it could be seen that the evolution of value bolt supplementary bending moment $\Delta \mathrm{Mb}$ at slotted holed assembly is quite different than the normal holed ones. At normal holed assembly, the increasing value of $\Delta \mathrm{Mb}$ is proportional to the increasing distance of bolt's eccentricity. Whereas, at slotted holed assembly, the greatest value of $\Delta \mathrm{Mb}$ is reached when the bolt is located at the middle of slotted hole, in other words, bolt position $=0.5$. The range of maximum and minimum $\Delta \mathrm{Mb}$ value is also different, the vast range of $\Delta \mathrm{Mb}$ value could be found at normal holed assembly, whereas a much smaller range of $\Delta \mathrm{Mb}$ value is found at slotted holed assembly.

Finally, we can conclude that the better fatigue resistance could be achieved by using a slotted holed part at the bolt position whose front contact surface is the same or smaller than its back contact surface, in other words the bolt position $\leq 1$. This choice will reduce the value of $\Delta \mathrm{Mb}$ and eventually affect significantly the reduction of fatigue stress produced.

\section{The maximum value of external force could be restrained by the assembly}

Finally, from the simulations have been done, we could find out the maximum value of force external could be restrained by the assembly for each parameter variation as the function of the preload applied. In order to facilitate the reading of maximum external force, we will multiply ratio Fe/Q to the $\mathrm{Q}$ (pre-stress applied at the bolt).

The curves generated are shown on figure 21-23, it is shown at modulus Young ratio 1 and 1.5, maximum external force while the bolt is positioned on other than bolt position= 1 is slightly the same. Except for bolt position $=1$, where maximum external force applied could be restrained by the assembly is achieved. In other hand, at modulus Young ratio $=0.5$ we could see differences of maximum external force among the variation of bolt position. Generally, a lower modulus Young ratio will always result in the augmentation of fatigue resistance of the assembly. From those three figures (figure 21-23), there is a decreasing trend of maximum external force could be rstrained when we increase the modulus Young ratio. Therefore, on the design process, one should take into account these ratio and minimize this value as lower as possible.

\section{E. The data interpolation in order to visualize the evolution of maximal external force value}

By using the Matlab® the evolution curve of maximum external force could be achieved. Firstly, the curves of each bolt position are plotted. Afterwards, values from each bolt variation are interpolated and finally will form a surface such as shown on the figure 24,25 , and 26. The objective of this interpolation is to facilitate the reading of maximum external force could be restrained by the assembly for each variation of modulus Young ratio.

The increasing value of modulus Young ratio results in the reduction of assembly's maximum external force which is proved by the surface shifting down as the modulus Young ratio increasing. These interpolation processes could be refined if the bolt variation interval is made as smaller as possible.

\section{CONCLUSION}

In this paper, the finite elements model has been developed and validated as well. The model is then used in order to understand the behavior evolution of the assembly as some assembly's parameters are being varied. Such parameters varied are the bolt position and modulus Young ratio of bolt and parts. Another parameter such as pre-stress variation does not interest us anymore, because by using dimensionless parameters developed by Turgeon and Vadean and keeping constant the geometrical proportion the same behavior are found when this parameter varied.

We could conclude that, at slotted holed bolted joint assembly, the fatigue stress produced at the bolt evolutes significantly with the variation of bolt position and also the modulus Young ratio of bolt and parts. A reduced value of fatigue stress produced will be achieved while the bolt position is the nearest possible with respect to the point where load applied. Whereas, a higher modulus Young ratio will convict a higher fatigue stress produced at the bolt.

After having compared the slotted holed assembly with the normal holed one, we could find a lower fatigue stress produced at the slotted holed assembly while the bolt is located at the bolt position other than 1. At the bolt position $=1$, there is only slight difference of fatigue stress produced between those two assemblies (normal and slotted holed). Therefore it would be reasonable using slotted holed assembly and locating the bolt other than bolt position= 1 so that the reduction in term of fatigue stress produced could be achieved.

\section{ACKNOWLEDGEMENT}

I would like to express my gratitude to my supervisor in INSA Toulouse Monsieur Alain Daidié who had guided me in this research in spite of my different study background with regard to the subject of the research. I also would like to thank Sepuluh Nopember Institute of Technology (ITS) who had given a golden chance to continue my master study at Université de Touluse III (Université Paul Sabatier) along with Program Beasiswa Unggulan Kementrian Pendidikan Nasional Republik Indonesia which has funded my study abroad.

\section{REFERENCES}

[1]. Bakhiet, E.M., "Etude des assemblage boulonnés à chargement fortement excentre soumis à des solicitation de fatigue", thèse à l'INSA de Toulouse, Toulouse, France, 1994.

[2]. Turgeon F, Vadean A. New Modelling Approach for Preloaded Bolted Joints Submitted to Cyclic Loading, Part I: Dimensionless Parameters Study 
[3]. Turgeon F, Vadean A. New Modeling Approach for Preloaded Bolted Joints Submitted to Cyclic Loading, Part II : Analytical, Numerical and Experimental Validation

[4]. J. Chakhari. Modélisation d'une fixation par éléments filetés. Etude d'une structure à forte excentration de chargement et soumise à des sollicitations en fatigue. Thèse de l'INSA

[5]. Alkatan, Feras. Modélisation des raideurs des assemblages par éléments filetés précontraints. Thèse de l'INSA

[6]. Guillot, Jean. Dossier Technique de l'ingénieur, Calcul des assemblages vissés -Assemblages chargés axialement.

[7]. Guillot, Jean. Modélisation et Calcul des Assemblages Vissés Géneralités.

[8]. Guillot, Jean. Calcul des Assemblages Vissés - Assemblage Soumis à une Charge Excentrée: Partie 1.

[9]. Guillot, Jean. Calcul des Assemblages Vissés - Assemblage Soumis à une Charge Excentrée: Partie 2.

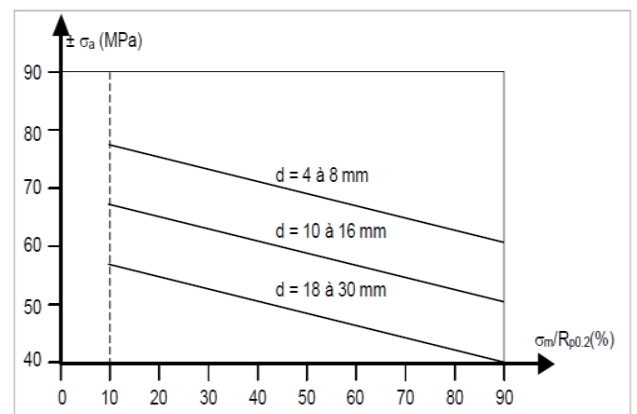

Figure 1. Haigh Diagram describing the fatigue stress $\sigma a$ as the function of $\sigma \mathrm{m} / \mathrm{Rp} 0.2$ for the screw with class : $8.8,10.9$ and 12.9

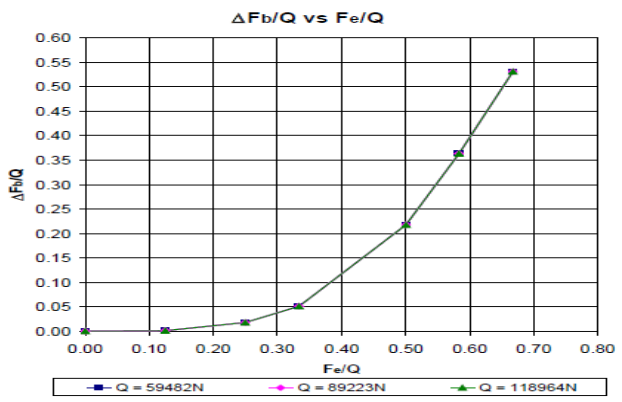

Figure 2. The curve $(\triangle \mathrm{FB} / \mathrm{Q})$ versus $(\mathrm{FE} / \mathrm{Q})$ with different applied preloads

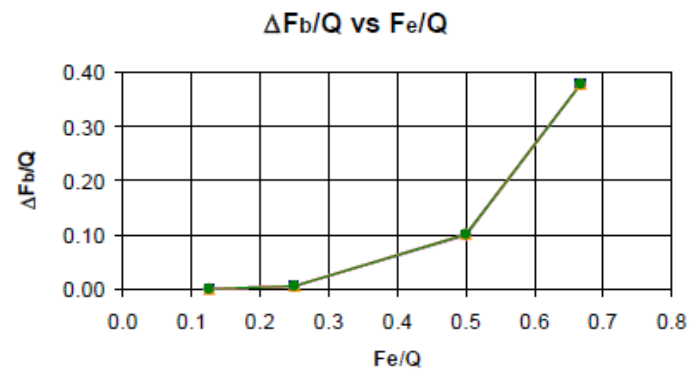

- Dnom $=5 \mathrm{~mm} \rightarrow$ Dnom $=8 \mathrm{~mm} \rightarrow-$ Dnom $=12 \mathrm{~mm} \rightarrow-$ Dnom $=16 \mathrm{~mm}$

Figure 3. The curve $(\Delta \mathrm{FB} / \mathrm{Q})$ versus $(\mathrm{FE} / \mathrm{Q})$ with different nominal diameters

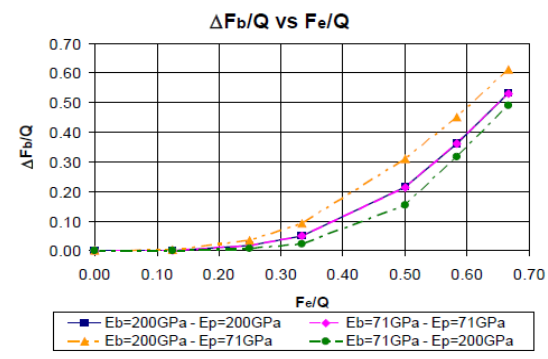

Figure 4. Curve $(\triangle \mathrm{FB} / \mathrm{Q})$ as the function $(\mathrm{FE} / \mathrm{Q})$, with the different ratio ofEBolt/EPart
[10]. Daidie A, Chakhari J, Zghal A. Numerical Model for Bolted Tstubs with Two Bolt Rows.

[11]. European standard E25-030, Fasteners. Threaded connections Design, calculation and mounting conditions, AFNOR Publications, 2nd version, February 1988, ISSN 0335-3931

[12]. NF E27-009 norm, Fasteners - Fatigue test under axial load, AFNOR Publications, 1st Edition, October 1979, 1-10.

[13]. Sayettat et al, Assemblages boulonnés : Conception et montage, CETIM, 1980.

[14]. Lieurade H.P., Complément en fatigue des boulonset assemblage boulonnés en construction métallique, Assemblages, CETIM Octobre 1977.

[15]. Guillot J., "Assemblages par élémentsfiletés. Calcul," in Techniques de l'Ingénieur, traité Mécanique et Chaleur, Paris, France, 1989, pp. B5 560 - B5 562.

[16]. ISO 7091 : 2000, Plain Washers - Normal Series - Product grade C, CEN, Octobre 2000.
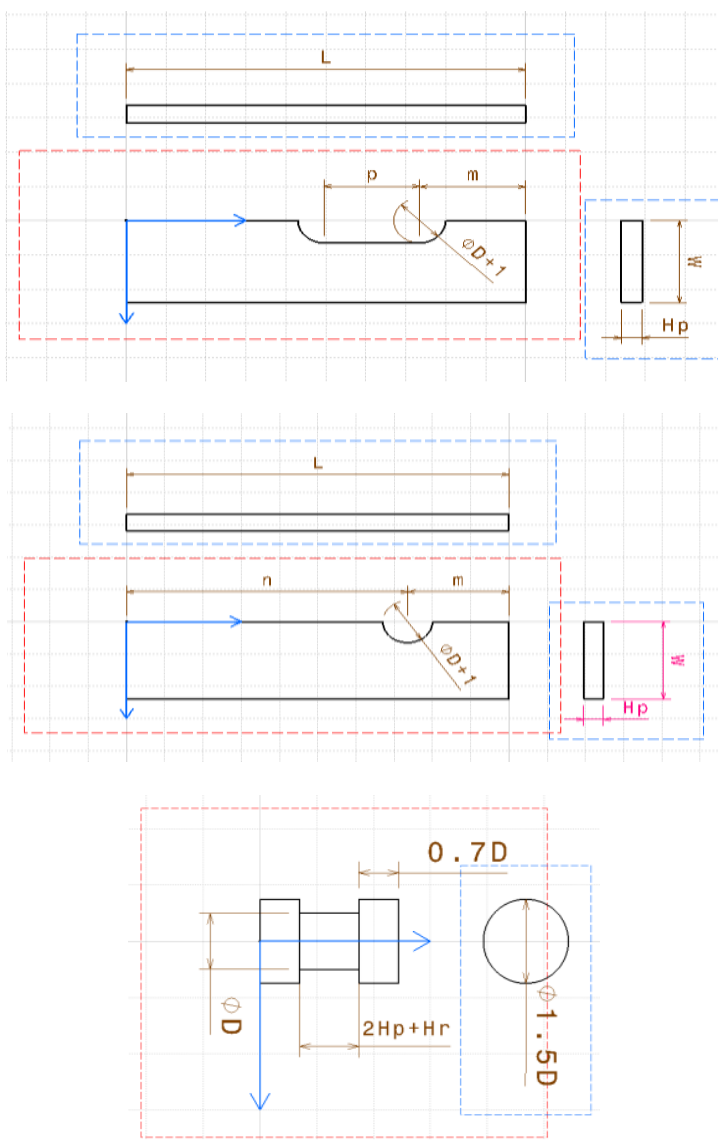

Figure 5. Sketch of Parts and Bolt

Parameters Explanation:

$\mathrm{m}$ :distance between the bolt's axis and the end of the part which is not being applied by the force

$\mathrm{n}$ : distance between axis of the bolt and the end of part where load is being applied (force eccentricity)

Hp: Part thickness

Hr: Washer thickness

2W: Part width

Dh: Hole diameter

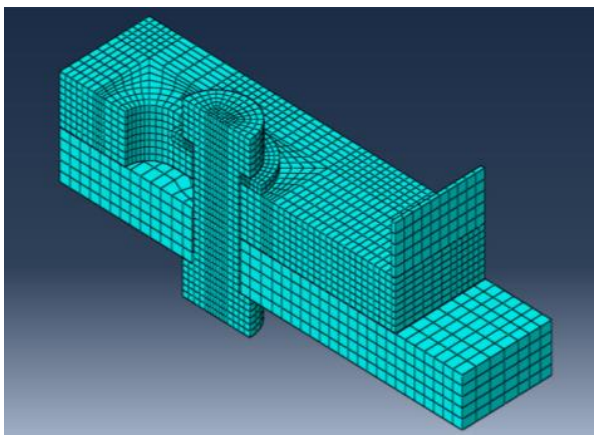

Figure 6. Mesh of total assembly 


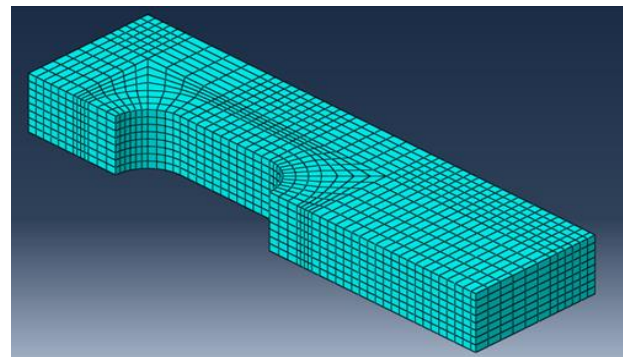

Figure 7. Mesh of slotted holed part mesh

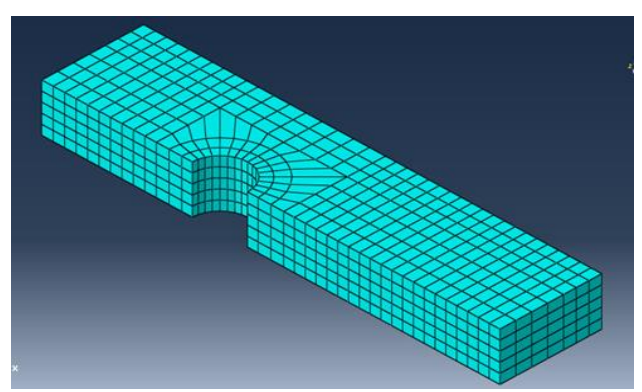

Figure 8. Mesh of normal holed part

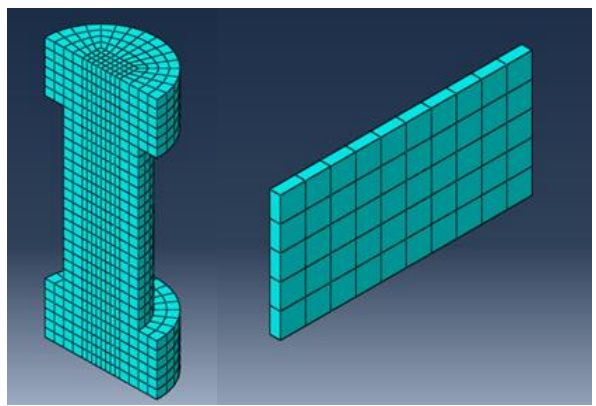

Figure 9. Mesh of bolt and force support

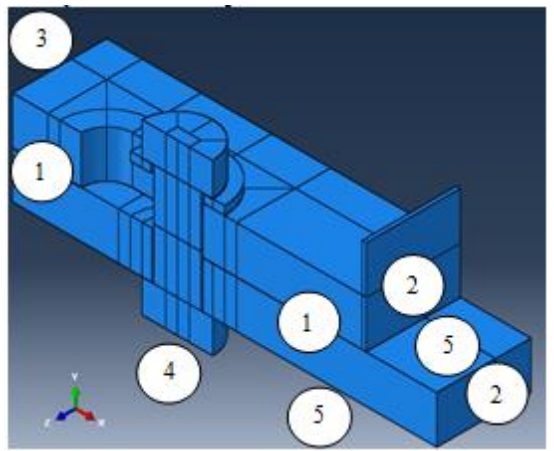

Figure 10. Boundary conditions of the model

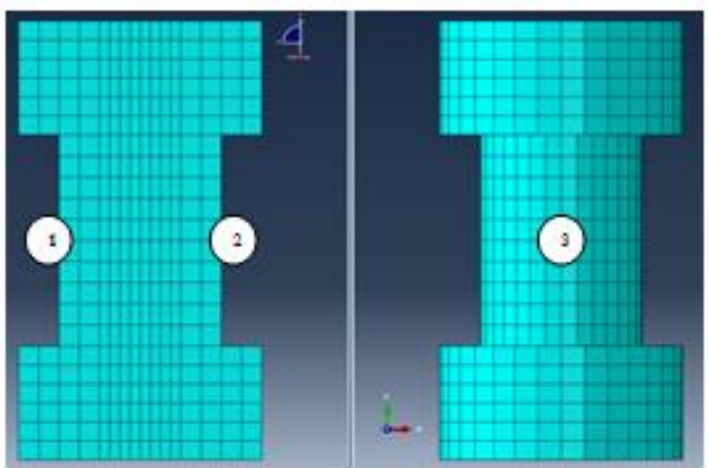

Figure 11. Three control points of bolt

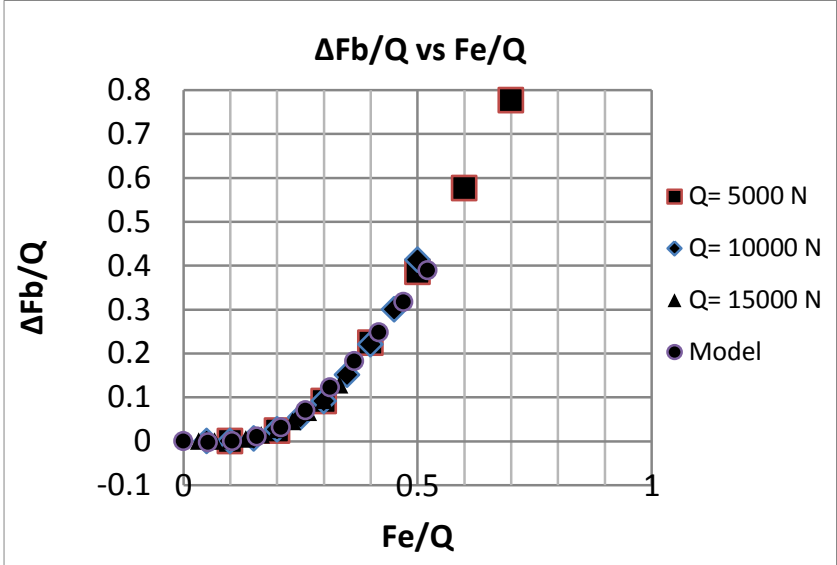

Figure 12. $\Delta \mathrm{F}_{\text {bolt }} / \mathrm{Q}$ versus $\mathrm{F}_{\text {external }} / \mathrm{Q}$ curve

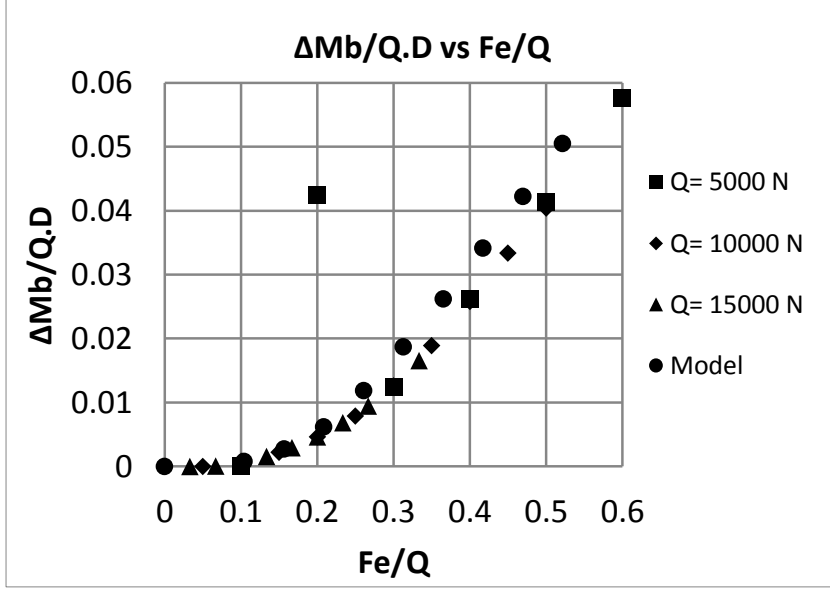

Figure 13. $\Delta \mathrm{M}_{\text {bolt }} / \mathrm{Q} . \mathrm{D}$ versus $\mathrm{F}_{\text {external }} / \mathrm{Q}$ curve

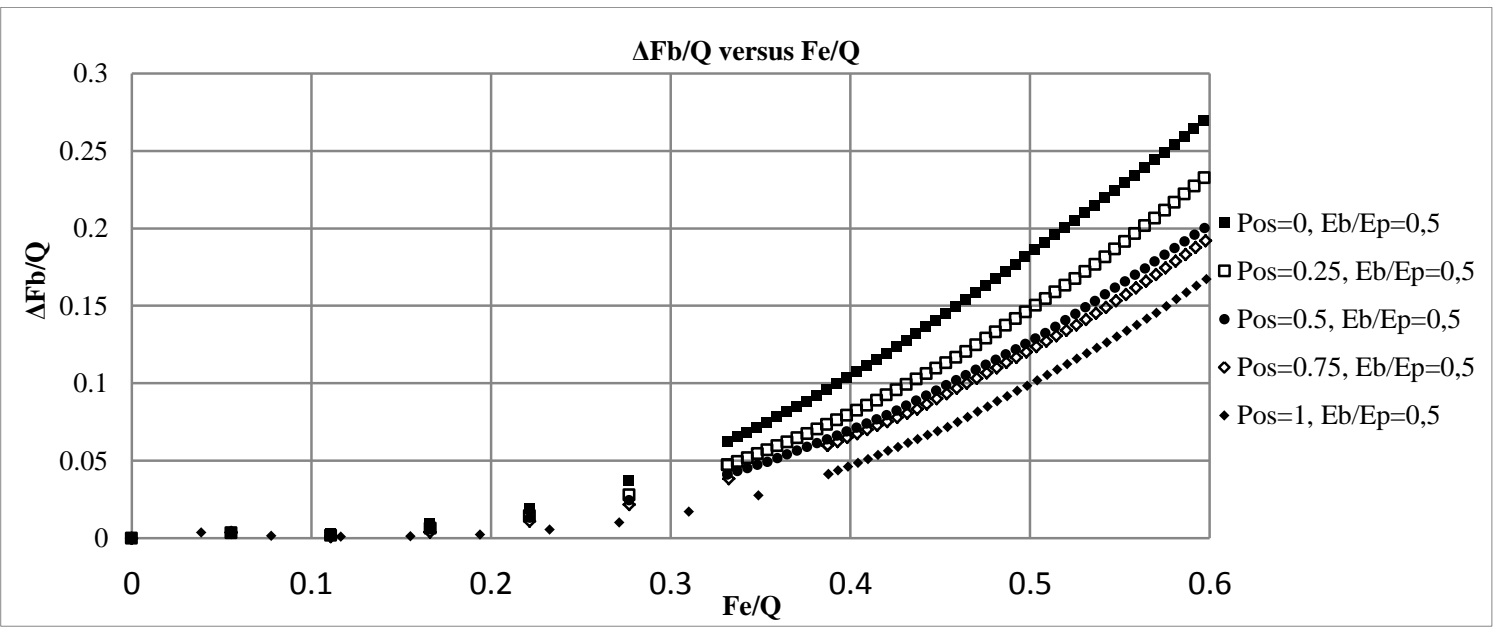

Figure14. Curve $\Delta \mathrm{Fb} / \mathrm{Q}$ versus $\mathrm{Fe} / \mathrm{Q}$ for modulus Young ratio 0.5 


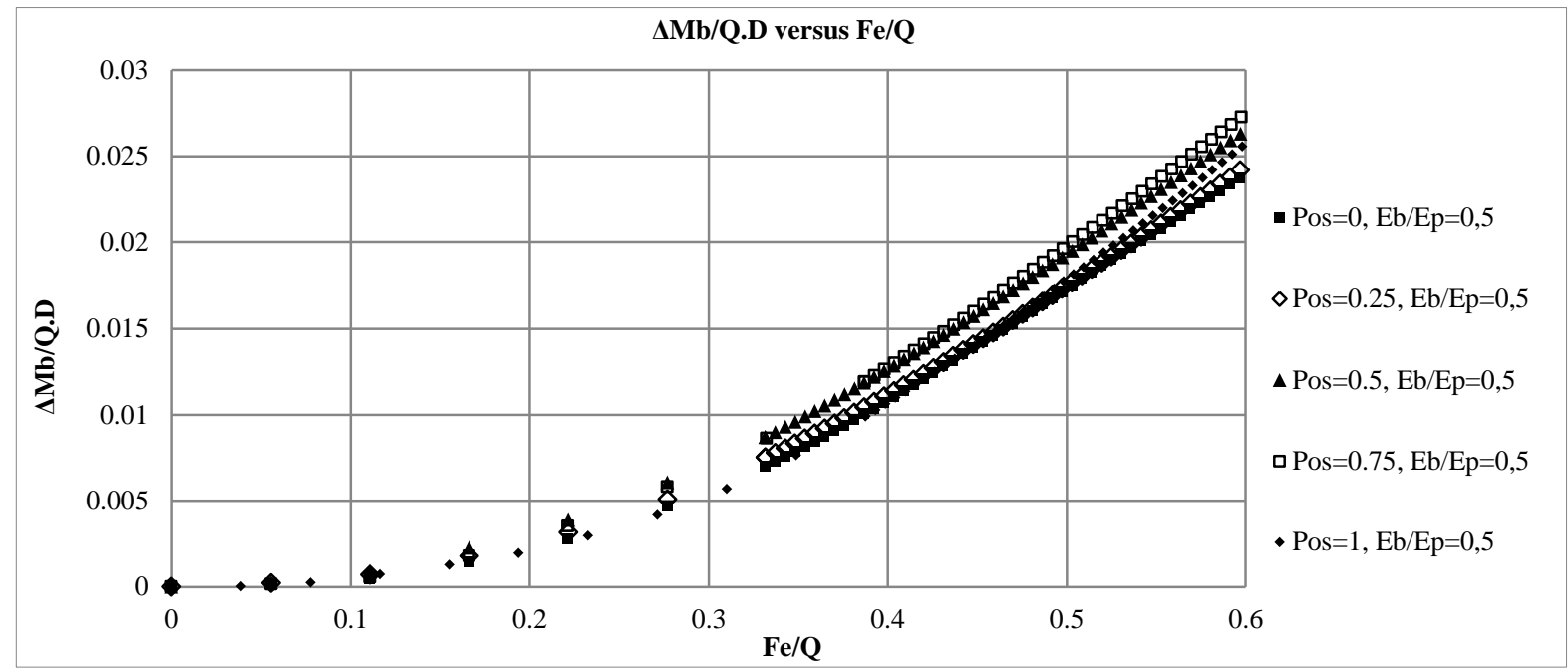

Figure 15. Curve $\Delta \mathrm{Mb} / \mathrm{Q}$.D versus $\mathrm{Fe} / \mathrm{Q}$ for modulus Young ratio 0.5

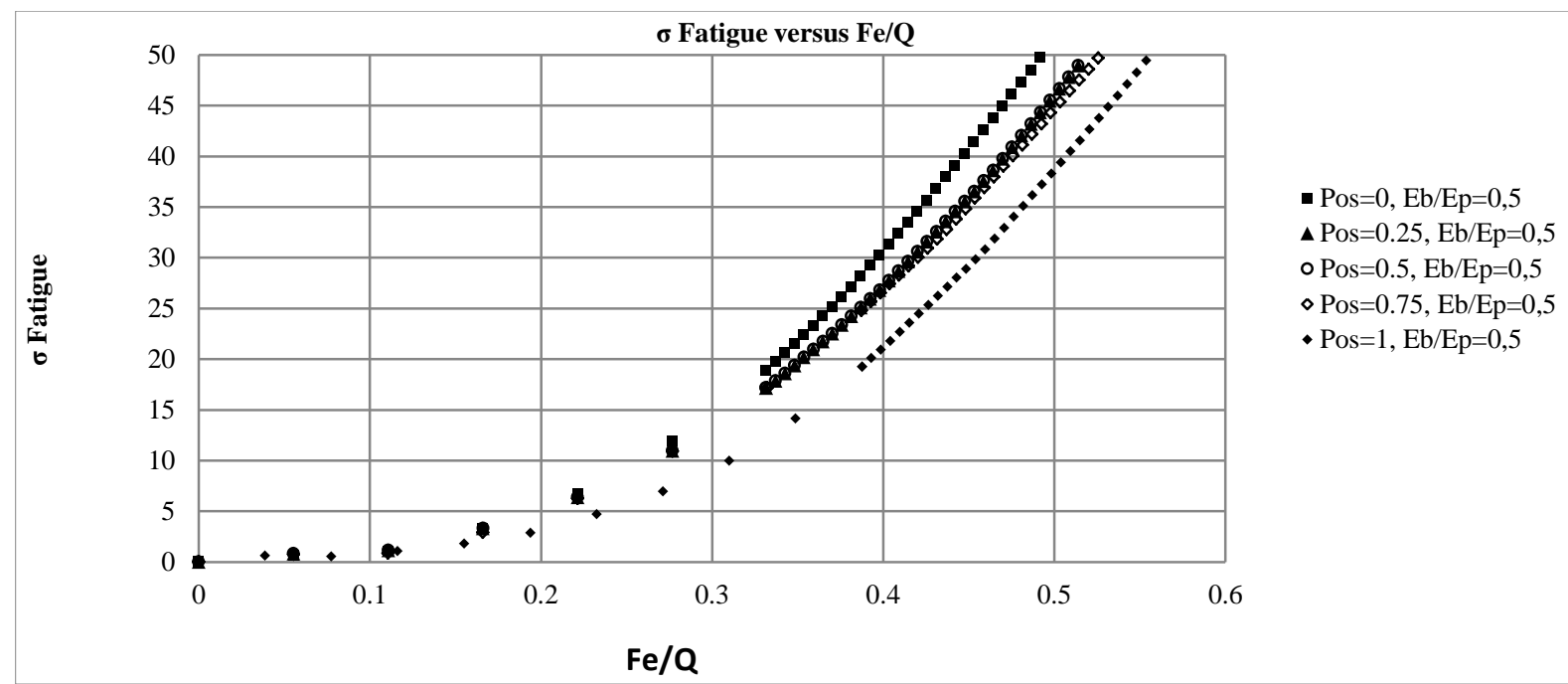

Figure 16. Curve $\sigma$ Fatigue versus Fe/Q for modulus Young ratio 0.5

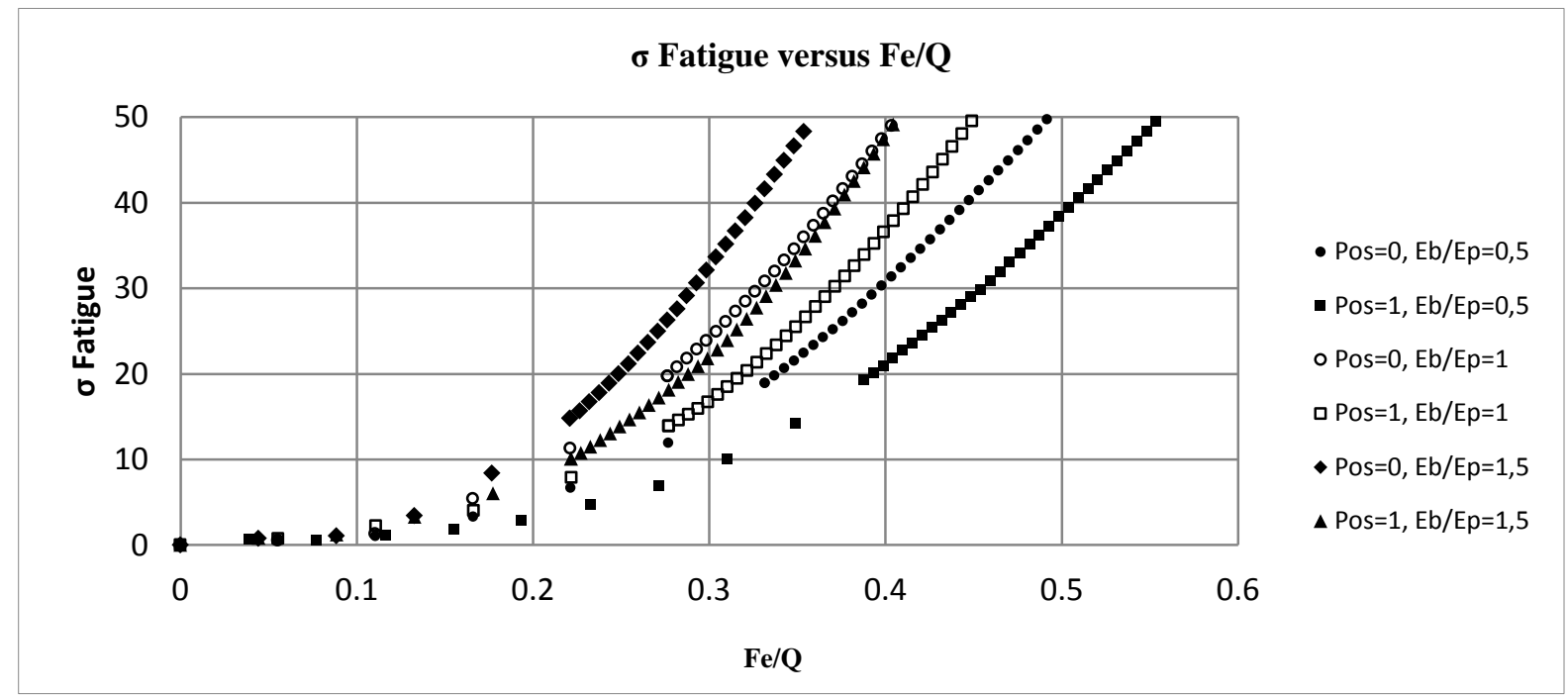

Figure 17. Curve $\sigma$ Fatigue versus Fe/Q for different value of modulus Young ratio 


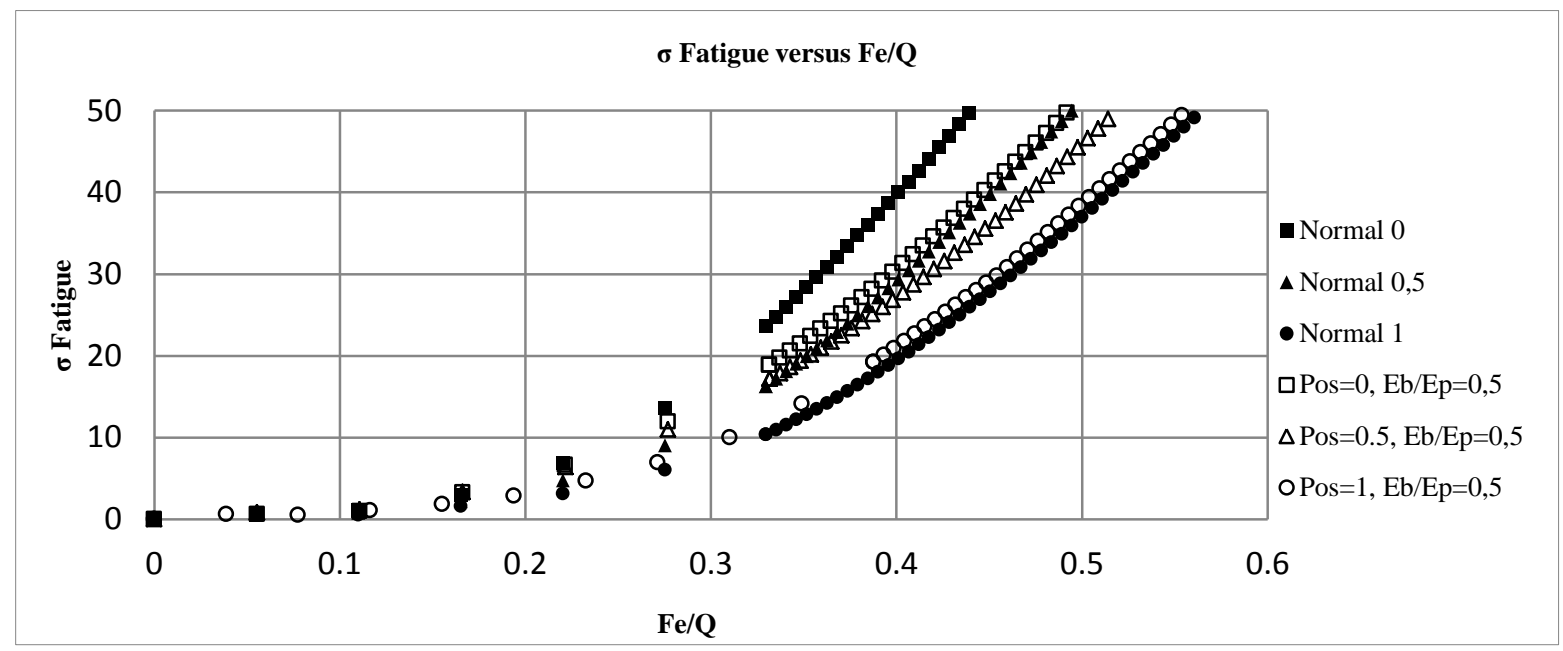

Figure 18. Comparison curve $\sigma$ Fatigue versus Fe/Q of normal and slotted holed part

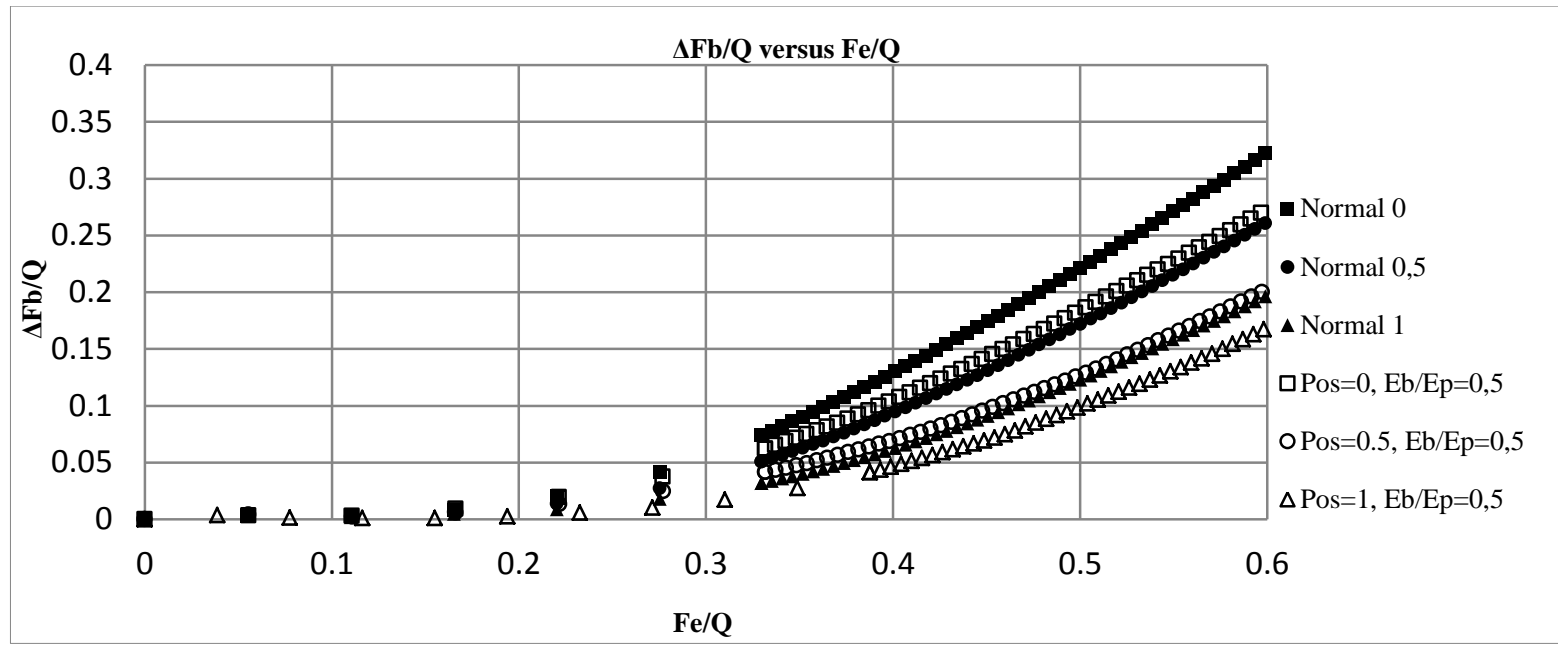

Figure 19. Comparison curve $\Delta \mathrm{Fb} / \mathrm{Q}$ versus $\mathrm{Fe} / \mathrm{Q}$ of normal and slotted holed part

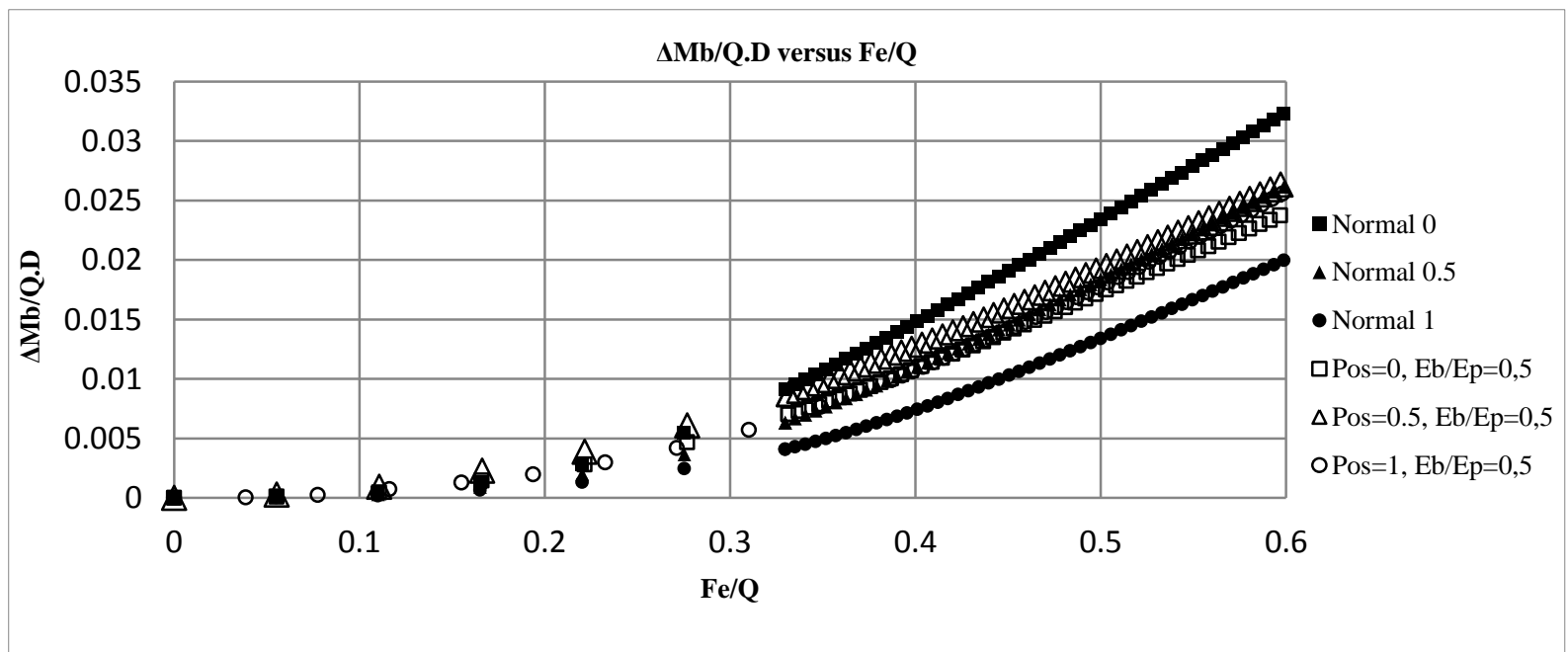

Figure 20. Comparison curve $\Delta \mathrm{Mb} / \mathrm{Q} . \mathrm{D}$ versus Fe/Q of normal and slotted holed part 


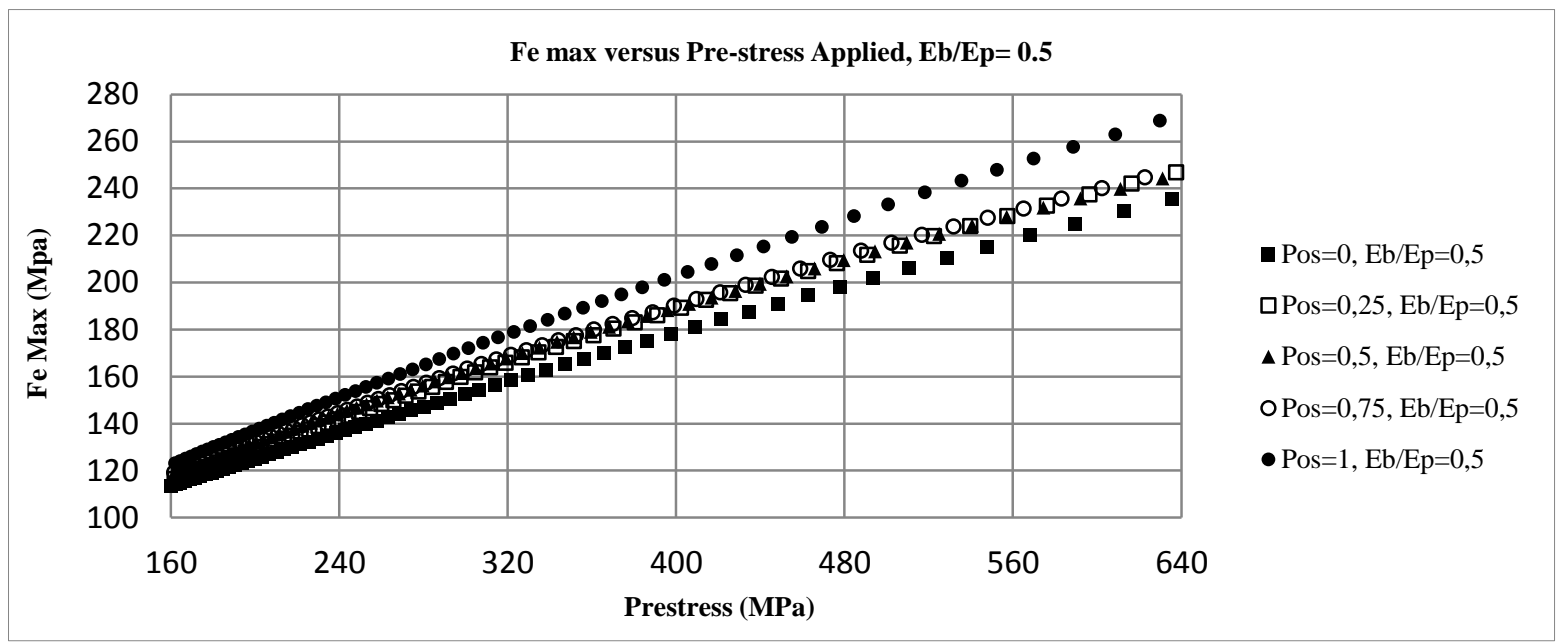

Figure 21. Curve maximum external force versus pre-stress applied for modulus Young ratio 0.5

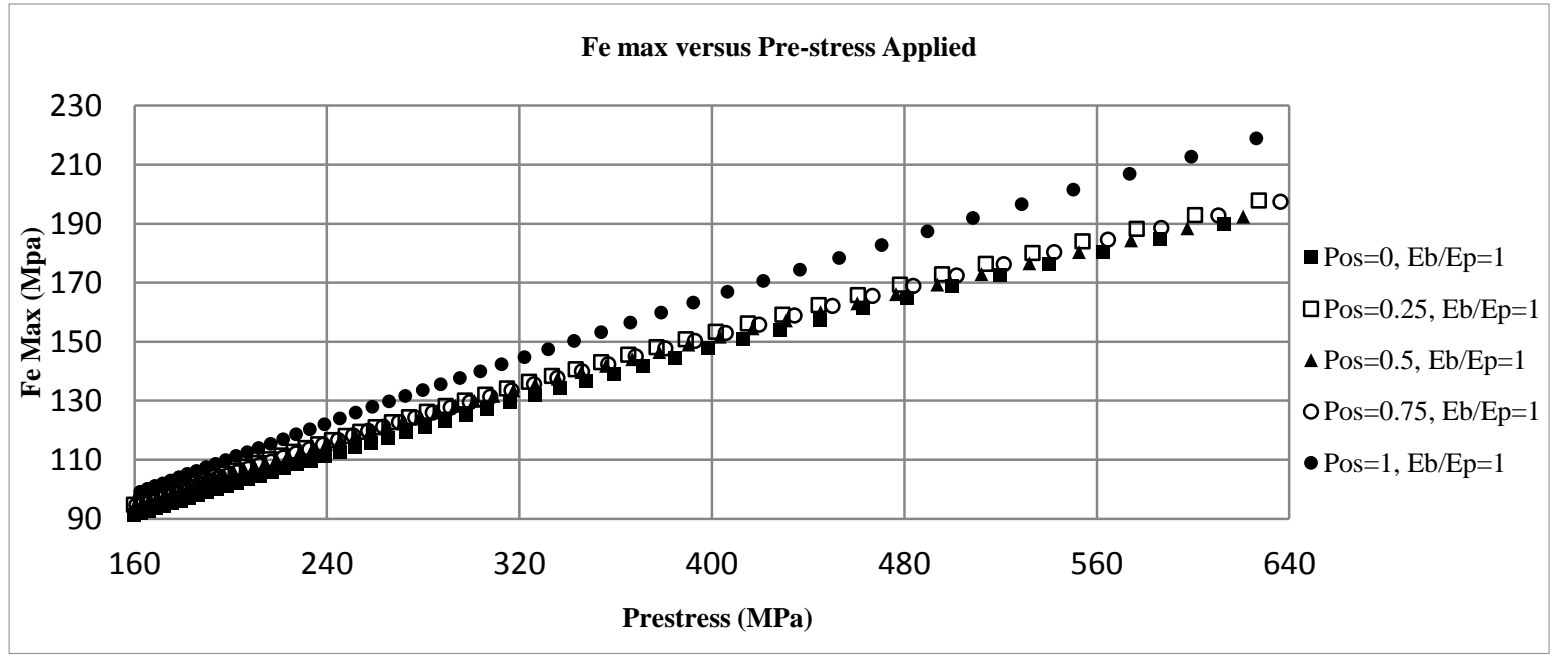

Figure 22. Curve maximum external force versus pre-stress applied for modulus Young ratio 0.5

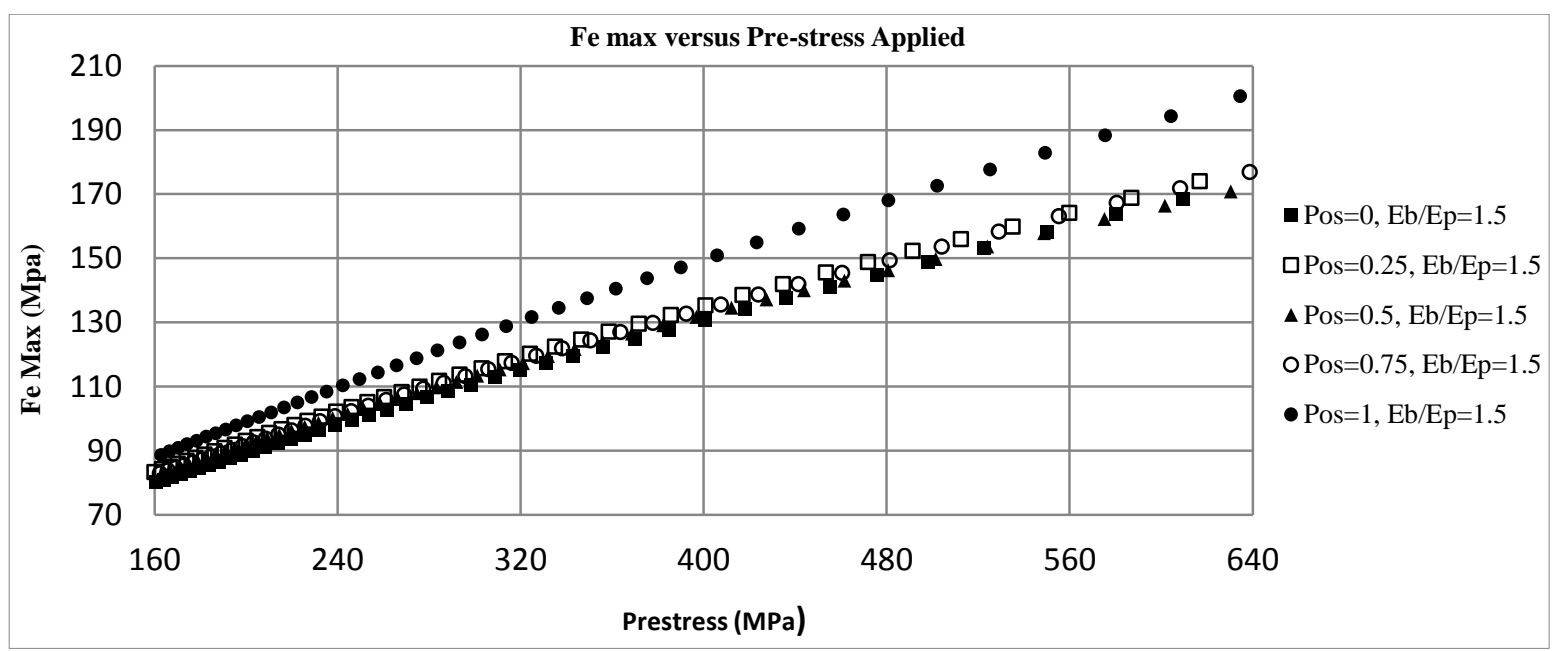

Figure 23. Curve maximum external force versus pre-stress applied for modulus Young ratio 0.5 


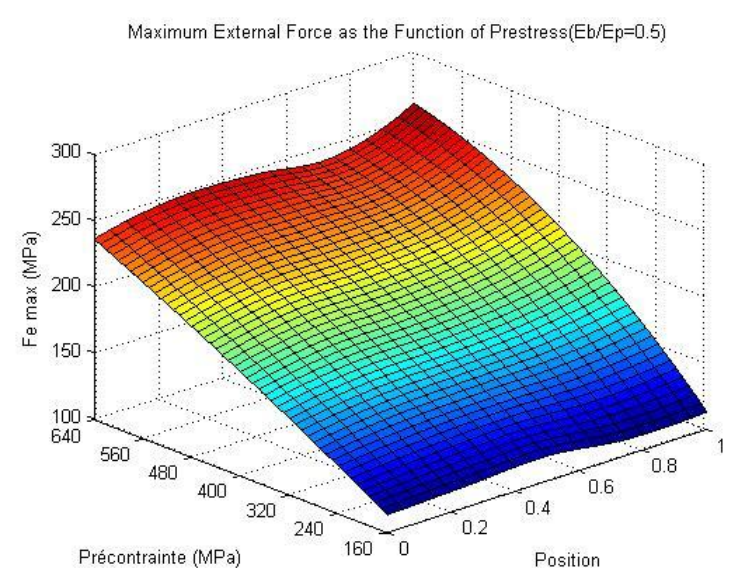

Figure 24. Evolution curve of maximum external force versus prestress applied for modulus Young ratio 0.5

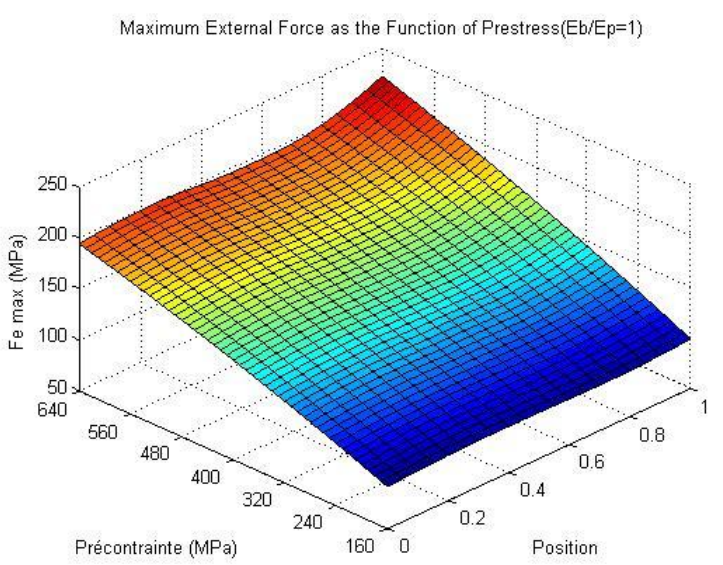

Figure 25. Evolution curve of maximum external force versus

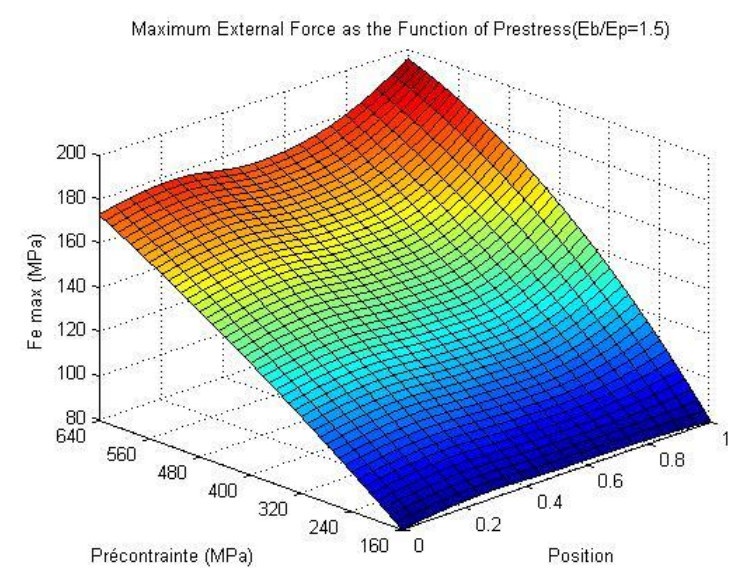

Figure 26. Evolution curve of maximum external force versus prestress applied for modulus Young ratio 1.5
TABLE 1.

GEOMETRICAL DIMENSIONS

\begin{tabular}{ccccccc}
\hline \hline $\mathbf{L}(\mathbf{m m})$ & $\begin{array}{c}\mathbf{n} \\
(\mathbf{m m})\end{array}$ & $\begin{array}{c}\mathbf{h p} \\
(\mathbf{m m})\end{array}$ & $\begin{array}{c}\mathbf{2 W} \\
(\mathbf{m m})\end{array}$ & $\begin{array}{c}\mathbf{D} \\
(\mathbf{m m})\end{array}$ & $\begin{array}{c}\text { Dh } \\
(\mathbf{m m})\end{array}$ & $\begin{array}{c}\mathbf{m} \\
(\mathbf{m m})\end{array}$ \\
\hline 90 & 66 & 12 & 48 & 12 & $\mathrm{D}+1$ & 24 \\
& 61.5 & & & & & 28.5 \\
& 57 & & & & & 33 \\
& 52.5 & & & & & 37.5 \\
& 48 & & & & & 42 \\
\hline \hline
\end{tabular}

TABLE 2.

GEOMETRICAL DIMENSIONS

\begin{tabular}{ccccc}
\hline \hline 1 & Titanium Alloy & 105000 & 0.3 \\
& Steel & 210000 & 0.3 \\
& Titanium Alloy & & 105000 & 0.3 \\
\hline \hline No & Part Material & Ep (Mpa) & $\mathbf{v}$ & $\mathbf{E b / E p}$ \\
\hline 1 & Steel & 210000 & 0.3 & 0.5 \\
2 & Steel & 210000 & 0.3 & 1 \\
3 & Aluminium & 70000 & 0.3 & 1.5 \\
\hline \hline
\end{tabular}

TABLE 3.

THE TYPE AND NUMBER OF ELEMENTS

\begin{tabular}{ccc}
\hline \hline Part & $\begin{array}{c}\text { Number of } \\
\text { Element }\end{array}$ & Element Type \\
& 5448 & $\begin{array}{l}\text { Linear hexahedral } \\
\text { elements, C3D8R }\end{array}$ \\
\hline Slotted Holed Part & 1410 & $\begin{array}{l}\text { Linear hexahedral } \\
\text { elements, C3D8R }\end{array}$
\end{tabular}

Bolt

1536

Linear hexahedral elements, C3D8R
Washer

Force Support
130
Linear hexahedral elements, C3D8R

Linear quadrilateral elements, R3D4 